\title{
Extent of Asymptomatic Plasmodium spp. Infections and Associated Risk Factors at Household and Individual Levels in Korhogo Health District, Northern Côte d'Ivoire: implications for Malaria Control
}

Edjronké Marc Alexis Benié ( $\square$ beniemarcalexis@gmail.com )

UNIVERSITE FELIX HOUPHOUET-BOIGNY, ABIDJAN, COTE D'IVOIRE https://orcid.org/0000-0001-97293548

Kigbafori D. Silué

Université Felix Houphouët-Boigny, Unité de Formation et de Recherche Biosciences, Laboratoire de Biologie et Santé, Abidjan, Côte d'Ivoire. Centre Suisse de Recherches Scientifiques en Côte d'Ivoire.

\section{Lasme J. C. E. Esso}

Centre Suisse de Recherches Scientifiques en Côte d'Ivoire

Jean T. Coulibaly

Université Félix Houphouët-Boigny, Unité de Formation et de Recherche Biosciences, Laboratoire de Biologie et Santé, Abidjan, Côte d'Ivoire. Centre Suisse de Recherches Scientifiques en Côte d'Ivoire.

Kouamé I. Kouadio

Centre Suisse de Recherches Scientifiques en Côte d'Ivoire

karim Tuo

Institut Pasteur, Côte d'Ivoire

Constant G. N. Gbalégba

Unité de Formation et de Recherche Sciences de la Nature, Université NanguiAbrogoua, Abidjan, Côte d'Ivoire. Centre Suisse de Recherches Scientifiques en Côte d'Ivoire

Aboudraman Kaba

Centre Suisse de Recherches Scientifiques en Cote d'Ivoire

\section{Yao E. Kouakou}

Centre Suisse de Recherches Scientifiques en Côte d'Ivoire

\section{Serge-Brice Assi}

Programme National de Lutte contre le Paludisme, Ministère de la Santé et de Hygiène Publique, Côte d'Ivoire

\section{Bassirou Bonfoh}

Centre Suisse de Recherches Scientifiques en Côte d'Ivoire Xavier C. Ding 
Foundation for innovative new diagnostics, Geneva, Switzerland

\section{Eliézer K. N’Goran}

Université Félix Houphouët-Boigny, Unité de Formation et de Recherche Biosciences, Laboratoire de Biologie et Santé, Abidjan, Côte d'Ivoire. Centre Suisse de Recherches Scientifiques en Côte d'Ivoire.

\section{Research Article}

Keywords: Plasmodium spp., asymptomatic, LAMP, microscopy, household, individual, risk factor, Korhogo, Côte d'Ivoire

Posted Date: May 5th, 2021

DOl: https://doi.org/10.21203/rs.3.rs-444652/v1

License: (c) (i) This work is licensed under a Creative Commons Attribution 4.0 International License. Read Full License 


\section{Abstract}

Background: Plasmodium spp. asymptomatic carriers are potential reservoirs contributing to the persistence of malaria transmission in endemic areas. The study was designed to assess the extent of Plasmodium spp. asymptomatic infection at household and individual levels and associated risk factors in Northern Côte d'Ivoire.

Methods: A cross-sectional survey was conducted in July 2016 at household level in the health district of Korhogo. A questionnaire was administered to household's head to capture socio-demographic information and practices including malaria treatment and preventive measures. In each household, adults without malaria symptoms nor history of fever during the week before recruitment were screened. Capillary blood samples were collected and used for the detection of Plasmodium spp. infections using both conventional microscopy and a loop-mediated isothermal DNA amplification (LAMP) assay. Logistic regression was used to determine variables that influenced Plasmodium spp. asymptomatic infections.

Results: In total, 376 households and 1'011 asymptomatic adults were screened.

Asymptomatic Plasmodium spp. infections were identified in 12.5\% [47/376] and 38.3\% [144/376] of the households and in 5.2\% [53/1011] and 18.8\% [190/1011] of the individuals screened, according to microscopy and LAMP, respectively. At household level, asymptomatic carriers increased about two times when using mosquito repellent coils compared to those where it is not used (OR: 1.8; $p=0.005)$. At individual level, men's risk to be infected was about two times that of women (OR: 1.9; $p<0.001)$. The odd to be infected was also two times higher in population living in periurban areas compared to those leaving in the urban center (OR: 2.3; $p<0.001$ ). Additionally, age appear to be risk factor, with younger individuals being at higher risk of infection than elders (OR: $0.5 ; p=0.001)$.

\section{Conclusion}

Plasmodium spp. asymptomatic carriers is important in Northern Côte d'Ivoire and male, age under 30 and perirban living area appear as significant risk factors. Interventions aiming at eliminating asymptomatic infections in this context, should primarily target among other strategy, the at-risk populations and zones.

\section{Background}

Reinforced antimalarial interventions led to a global decline of this disease since 2000 (1). As a result, Plasmodium spp. infections tend to become gradually restricted to foci of residual transmission in settings with declining malaria transmission. Capitalizing on this success, the World Health Organisation (WHO) has adopted a Global Technical Strategy for the 2015-2030 period with the ambitious goal to reduce malaria mortality by $90 \%$ by 2030 (2). This strategy acknowledges that successful control and elimination strategies need to specifically target transmission reservoirs. Such reservoirs include asymptomatic carries, which typically harbor hard-to-detect low density infections, that can, nevertheless, contribute significantly to malaria transmission in such settings (3). 
Asymptomatic infection is defined by the WHO malaria terminology as the presence of asexual parasite in the blood without any fever or malaria-related symptoms (4). Asymptomatic carriage of $P$. falciparum may protect against clinical malaria (5). However, this infection is often undetected and untreated, resulting in a significant source of gametocytes for the transmission of the disease by local mosquito vectors (6). Asymptomatic carriage of $P$. falciparum is not detected by routine heath care system and require active case detection strategies using highly-sensitive diagnostic tools (7).

Molecular diagnostics have shown that this asymptomatic parasitic reservoir is more widespread than expected, even in low-endemic areas (8). Strategies that specifically target this parasite reservoir are therefore needed to accelerate malaria elimination in low- and medium-transmission settings (9). However, in some countries, such as Côte d'Ivoire, national policies have not yet specifically targeted asymptomatic carriers of Plasmodium spp. for planning antimalarial elimination interventions (10).

Côte d'Ivoire remains a malaria endemic country (11), where malaria transmission is stable and occurs throughout the year, while morbidity increases during the rainy season (12). A National cross-sectional survey conducted in 2012, in school age children, reported an average prevalence as high as $70 \%$ (13). The National antimalarial policies have been improved over the last decade to reinforce control measures. Insecticide-treated nets (ITNs) have been widely distributed free-of-charge to the entire population through regular mass campaigns at the country level. In 2006, 370'000 ITNs were distributed and total of 30'000'000 were distributed between 2010 and 2014 (14). Thus, ITNs household coverage increased from 27\% in 2006 to $66 \%$ in 2012 and $95 \%$ in 2015. In parallel, malaria prevalence decreased from $43-33 \%$ from 2010 to 2014 (13). Building on this result, the national malaria control program (NMCP) aimed to halve the malaria morbidity by 2020 (14). In order to reach this target, the NMCP strategy is based on three pillars: (i) an appropriate diagnosis and an effective treatment of clinical cases; (ii) the distribution of ITNs free of charge among population, and (iii) the intermittent preventive treatment (IPT) during pregnancy (10).

This strategic plan is mainly focused on symptomatic cases, identified through a passive detection system within the health system. Intervention targets are youngest children and pregnant women in priority because they are at higher risk of clinical malaria (15). Asymptomatic infections are not specifically targeted in this strategic plan because of limited available resources which are currently targeted to better control until elimination-specific measures can be considered.

It has been shown that asymptomatic Plasmodium spp. infections are frequent in the country (16). In Korhogo, city of Northern Côte d'Ivoire, twenty years ago, a $70 \%$ prevalence of asymptomatic Plasmodium spp. infections has been reported (12); however, another study carry out in 2015, in the same city showed a prevalence below $20 \%$ and $7.7 \%$ during the rainy and dry season, respectively (10). Both studies have used routine malaria diagnostic tools for the detection of Plasmodium infections and are likely to have missed a significant number of low-density infections. Sensitive molecular techniques, based on nucleic acid amplification and providing much lower limit of detection (LOD) than routine diagnostic methods, in the order of magnitude of 0.02 parasite per microliter of blood $(\mathrm{p} / \mu \mathrm{L})$ at best, are available to detect 
Plasmodium infections (17). Simplified molecular assays, using loop-mediated isothermal amplification (LAMP), have also been developed and enable the sensitive detection of malaria infections, in the range of 1 to $5 \mathrm{p} / \mu \mathrm{L}$, in remote laboratories with limited equipment and capacity (18). Commercially available LAMP kits have shown a similar performance than PCR, especially when used in remote settings, making it a useful tool to investigate the prevalence of malaria infections, including asymptomatic low-density infections, in endemic areas (18).

Plasmodium spp. asymptomatic carrier are potential malaria reservoir that not considered in our national malaria policy because of limited resources. Theirs weights should underrate based on routine diagnosis test and LAMP test should be more suitable to detect asymptomatic. This study assesses the extent of asymptomatic Plasmodium spp. infections in Northern Côte d'Ivoire, based on result of a cross-sectional survey using both microscopy and LAMP diagnostic kits. We also investigated the risk factors associated with asymptomatic infections and discuss their relevance for malarial control interventions.

\section{Method}

\section{Study area}

The study was carried out from 17 to 28 July 2016 in the health district of Korhogo, North Côte d'Ivoire. The district population was estimated at 536851 inhabitants in 2014 (19). The climate is characterized by two seasons: a rainy season that occurs from May to October and a dry season from November to April. The yearly rainfall is $1200 \mathrm{~mm}$ and the average temperature is $26.6^{\circ} \mathrm{C}(20)$. A dam has been built in 1972 to provide water for irrigation of fields and market gardening. Anopheles gambiae is the most prevalent vector species in this district (20). Among malaria parasites, Plasmodium falciparum is the quasi-exclusive species, with rare cases of $P$. malariae and $P$. ovale also being reported (10).

\section{Study design and procedures}

The study is a cross-sectional household survey. As described in a recent study carried out in Korhogo (10), 390 households were randomly selected from 30 demographic zones. Three teams (each including a medical doctor or a nurse, a laboratory technician, and questionnaire administrator) have enrolled participants using a households-based approach for 10 days. The study area was divided into three parts: urban center, intermediate zone and periurban. Households located in town square were considered belong to urban center. Those were situated in a peripheral of this city were considered belong to periurban. Households between center and periurban areas were assigned to the intermediate zone (Fig. 1). Participant inclusion criteria were: (i) absence of fever (axillary temperature $>37.5^{\circ} \mathrm{C}$ ) or self-reporting history of fever during the last seven days; (ii) self-reporting less than two malaria-suggesting symptoms, such as headache, shiver, sweat, nausea, vomiting, dizziness, tiredness, abdominal pain; (iii) no selfreported use of antimalarial treatments over the four previous weeks; (iv) written informed consent of the participant. 
A questionnaire was addressed to the household's head or his/her representative. A finger-prick blood sample was collected for Plasmodium spp. infection detection by microscopy and LAMP. Participants without malaria symptom, positive for malaria diagnosis test were considered as asymptomatic Plasmodium spp. carriers.

\section{Ethical consideration}

The study was approved in 2016 by the National Ethic and Research Committee of Côte d'Ivoire (NCER) (N/Réf : 120/MSHP/CNER-dk), NMCP and the local health district authorities. In agreement with recommendations of NMCP pertaining to the national policy on the management of malaria cases, asymptomatic participants positive to Plasmodium spp. were not treated. All of them received ITNs. They were also advised, if any malaria symptom would appear, to rapidly present to a health centre for malaria diagnosis and, if needed, treatment.

\section{Data collection}

\section{Questionnaire}

A questionnaire relative to promiscuity (household size, household crowd), use of preventive measures (ITNs, mosquito's repellents coils and insecticide sprayed) and treatment seeking behaviour was addressed to the household's head or his/her representative. Socio-demographic data (sex and age) were recorded for all members of the selected household.

\section{Microscopy}

Microscopy is gold standard. It was used as routine malaria diagnosis test. A thick and thin blood film was made on a slide and air dried on site. This diagnostic was performed as described elsewhere (10) A slide was classified as negative if no Plasmodium asexual forms or gametocytes were found after counting 500 white blood cells.

\section{LAMP}

LAMP is a novel malaria diagnosis. According its similar performance as PCR (21), it was used in this study. A finger-prick blood sample was collected for Plasmodium spp. infection detection by LAMP (Loopamp ${ }^{\mathrm{TM}}$ MALARIA Pan/Pf Detection Kit, Eiken Chemical Company). Sixty $\mu L$ of capillary blood were collected from finger prick, immediately mixed with an equal volume of extraction buffer, stored at ambient temperature, until processed the same day for LAMP as described elsewhere and using a "boil and spin" sample preparation (22). The LAMP reactions were conducted according to the manufacturer's recommendations using a standard heat block and results were read under a UV lamp. Extracted DNA samples were first tested using a Pan LAMP assay detecting all human-infecting Plasmodium spp. All pan-positive positive samples were further tested using a $P$. falciparum specific LAMP assay (Pf LAMP). Samples were classified as negative (Pan LAMP negative), $P$. falciparum positive (Pan and Pf LAMP positive) or non-falciparum positive (Pan LAMP positive and Pf LAMP negative). 


\section{Data analysis}

Double data entry was done using the Epidata 3.1 software. Labelling, and data transcription was carried out from software SPSS 18.0.0. Statistical analysis was conducted using STATA 12.1. Data were analysed both at household and at individual levels. For both levels, the dwelling setting was also considered. A household with at least one member diagnosed as positive for Plasmodium infection was considered as positive.

Prevalence of asymptomatic carrier was determined with $95 \%$ confidence interval. Pearson chi-square or Fisher's exact tests was used to determine association between asymptomatic Plasmodium spp. infection prevalence and promiscuity, prevention, treatment seeking behaviour, sex, ages groups and dwelling setting. The age group defined were $\leq 30$ years, $31-40$ years and $>40$ years (23). Bivariate logistic regression was used to identify crude odds ratios (COR) of variables associated with Plasmodium spp. asymptomatic infection and multiple logistic regression model to identify adjusted odds ratios (aOR). Variables were considered significant when the $p$ value was $<0.05$.

\section{Results}

\section{Study population characteristics}

Out of 390 households visited, 376 were included in this study. Fourteen households without any eligible participant were excluded. A total of 1'149 individuals were screened for eligibility and 1'011 eligible participants were enrolled in the study. The 138 non-eligible participants were spread across the 14 excluded households and 61 included ones. All enrolled participants underwent malaria testing as described above (fig. 2).

\section{Household characteristics}

The mean number of people per households was 7.7 persons. The majority of households $(228 / 376$, $60.8 \%)$ had less than 8 residents. On average, there were about 2 persons per room. The average number of reported of malaria episode per year per household was 2.8. ITNs were owned by $62 \%(233 / 376)$ of households and almost all of them $(231 / 376,61.4 \%)$ declared to use them. Mosquito repellent coil and insecticide spray were used respectively by $56.9 \%(214 / 376)$ and $47.9 \%(180 / 376)$ of the households. A large majority of household $(229 / 376,60.9 \%)$ declared to attend health centre in first intention, when needing medical care (Table 1 ).

\section{Individual characteristics}

Table 2 summarizes the demographic data and Plasmodium spp. prevalence of the study population screened by microscopy and LAMP. The mean age of the study population was 35.1 (range, 18 to 87 years old) and the median age was 31 years. Women representing $69 \%\left(697 / 1^{\prime} 011\right)$ of the included population. Approximately half of the included participants $\left(501 / 1^{\prime} 011,49.6 \%\right)$ are from in the intermediate zone. 


\section{Household prevalence and risk factors}

Plasmodium spp. infections were detected in 12.5\% (47/376) and 38.3\% (144/376) of the households by microscopy and Pan LAMP, respectively. Prevalence of Plasmodium spp. was higher in household reporting using mosquito repellents than those not using any ( $14 \%$ versus [vs] $10.5 \%, p=0.306$ by microscopy and $44.4 \%$ vs $30.2 \%, p<0.005$ by LAMP) (Table 1 ). Among, households, which do not use mosquito repellents coils $(162 / 376,43.1 \%)$, few $(8 / 162,4.9 \%)$ used any malaria prevention measures; but ITNs and insecticide spray were used alone or both by almost all households (154/162, 95.1\%) (Table 3 ).

Household Plasmodium spp. infection risk is summarized in table 4. The risk to be infected in household using mosquito repellent coil compared to those not doing so increased slightly according to microscopy (OR 1.4, $p=0.308$ ) and about two-fold (OR 1.8, p=0.005) according to LAMP. Household risk to be infected were not associated to promiscuity, malaria morbidity and treatment seeking behaviour.

\section{Individual prevalence and risk factors}

Plasmodium spp. infections were detected in 5.2\% (53/1'011) of study participants by microscopy and in $18.8 \%\left(190 / 1^{\prime} 011\right)$ by LAMP. Pf LAMP revealed that $82.1 \%$ (156/190) of infection were due to Plasmodium falciparum and 17.9\% (34/190) were non-Plasmodium falciparum (Table 2). Among Plasmodium spp. carriers detected by LAMP, 22.6\% (43/190) were detected by microscopy and a large fraction $(147 / 190,77.4 \%)$ were missed. (Table 5$)$.

Plasmodium spp. infection prevalence was associated to younger age, men and periurban zone. It was more limited in older ( $>40$ years) than in younger ( $<30$ years) study participants $(5.2 \%$ vs $5.9 \%, p=0.62$ by microscopy and $14.3 \%$ vs $24 \%, p=0.001$ by LAMP). Men were significantly more infected than women ( $7.3 \%$ vs $4.3 \%$ by microscopy, $\mathrm{p}=0.046$ and $25.8 \%$ vs $15.6 \%$ by LAMP, $p<0.001$ ). Plasmodium spp. infection prevalence increased significantly from urban center to intermediate and periurban zone $(3 \%$, $5.2 \%$ and $9.9 \%, p=0.004$ by microscopy and $14.8 \%, 18.2 \%$ and $28.5 \%, p=0.001$ by LAMP) (Table 2 ).

Individual's risk to be infected by Plasmodium spp. is summarized in table 6. Risk to be infected was practically similar for older ( $>40$ years) and younger (<30 years) according to microscopy (OR 0.9, $p=0.682)$ and reduced by half according to the LAMP $(O R 0.5, p=0.001)$. Compared to women, men are significantly more at risk of Plasmodium infection, by about two-fold (OR 1.7, $p=0.049$ by microscopy and OR 1.9, $p<0.001$ by LAMP). Compared to urban center, living in the periurban area increases from two- to three-fold the likelihood to be infected by Plasmodium spp. according to the microscopy and LAMP $(O R=3.6, p=0.002$ vs $O R=2.3, p<0.001)$.

\section{Discussion}

Asymptomatic carriers of Plasmodium spp. can act as parasite reservoirs that contribute to malaria transmission in some endemic areas. These infections are characterized by low parasitemia which frequently was missed by RDTs and microscopy. In this study, conducted in the city of Korhogo, Northern 
Côte d'Ivoire, we used microscopy and LAMP to assess the extent of asymptomatic Plasmodium spp. infections. We also investigated the risk factors associated with asymptomatic infections at household and individual level. This study included 1'011 individuals of 376 households.

In this population, the prevalence of asymptomatic Plasmodium spp. infection was found to be high, with slightly more than one third (38.3\%) of all included household having at least one infected individual and approximately one out of five individual (18.8\%) being infected overall when using LAMP for asymptomatic infection detection. Apparent prevalence by microscopy are only about a third of those by LAMP (12.5\% versus $38.3 \%$ at the household level, and $5.2 \%$ versus $18.8 \%$ at the individual level). This clearly indicates that any active case detection intervention would miss most of all infections if based on microscopy or other methods with similar LOD, such as rapid diagnostic tests. It is likely that a more sensitive method, such as LAMP, which could be successfully implemented for the screening activities described here, would allow to capture a vast majority of all these infections (24). Importantly, LAMP allowed here to screen a relatively high number of individuals, more than a thousand, over a short period of time, with more than 100 samples tested per day in average over 10 days, showing that this method is compatible with large-scale screening campaigns. It cannot be excluded that additional asymptomatic infections, below the LOD of LAMP, remained undetected, yet the transmissibility of such very low-density infections is unlikely to be significant and, by extension, detecting such infections is likely to be of limited relevance from a programmatic point-of-view. Whether the use of more sensitive methods than microscopy or RDT but also more ones, such as LAMP, is ultimately cost-effective for active case detection screening campaign remains to be determined. Although some studies show high sensibility of $\operatorname{LAMP}(21,25)$, its performance should be demonstrated in our context.

Our results show that both at household and individual level, asymptomatic carriers risk increased when moving from the urban center to the intermediate and periurban zones. It is well reported that malaria infections are more prevalent in the periurban setting compared to urban (26). The high risk of asymptomatic Plasmodium spp. infection in periurban setting was highlighted by another study (27). In our case, the high risk observed in periurban setting can be related to the presence of shallows suitable for agricultural activities including market gardening and irrigation rice field. These typically lead to several malaria vectors breeding sites (28). Previous studies have reported that, the low socioeconomic status observed in periurban areas (26), and living close to a permanent stagnant water (at a distance $<1$ $\mathrm{km}$ from the house) were more likely to increase the risk to be infected with malaria parasite (29).

Malaria prevention measures, particularly mosquito repellent coil, were used in more than half of household. Yet, household reporting the use mosquito repellent coil were found to be at greater risk of asymptomatic Plasmodium spp. infection, an apparently counter-intuitive observation. It can be hypothesized that coil use is prompted by the actual presence of mosquitos within or near the households in question but that these coils might be only partially effective at preventing bites. Indeed, mosquito mortality due to application of various mosquito coils averagely ranged between 24 and $64 \%$ (30). On the other hand, coil might simply not be used in households free of mosquitos, where the risk of infections would be lower to null. 
Age and gender are characteristics often significantly associated with specific risk of asymptomatic Plasmodium spp. infections $(23,31)$. Our study also found that, older age was associated with a reduction of asymptomatic Plasmodium spp. infection. Asymptomatic prevalence in age $<30$ years $(24 \%)$ declined significantly in age $>40$ years $(14.3 \%$, by LAMP). In stable malaria transmission areas, repeated contact with parasites, contribute to increase immunity with age (32).

Men were most likely to be infected than women $(25.8 \%$ vs $15.6 \%(p<0.001)$. It is possible that men may spend longer time outdoor during evening and thus are more exposed to risk of infection (33). A study performed in Eastern Myanmar associated men infection to professional activities. Individuals who worked as farmers or wood and bamboo cutters were found to be at increased risk of asymptomatic Plasmodium infection (23). In our case, it is possible that national control measures mainly focused women, as ITNs and IPT have been distributed free-of-charge during pregnancy, could partially explain this observation.

\section{Conclusion}

Plasmodium spp. asymptomatic infection is highly prevalent in Korhogo. Infection risks appear linked to dwelling setting, gender and age. Better controlling and ultimately eliminating malaria in Korhogo will require to take into consideration these asymptomatic infections. We report here that LAMP molecular assay could represent a valuable and potential cost-effective approach to tackle these infections. Our results also provide guidance as to which populations should be prioritized when investigating such infections and could serve to define specific elimination policies and more effective programmatic interventions in the future.

\section{Abbreviations}

WHO: World Health Organisation; ITNs: insecticide-treated mosquito net; NMCP: national malaria control program; IPT: intermittent preventive treatment; LOD: lower limit of detection; LAMP: Loop-mediated isothermal DNA amplification; cOR: crude odds ratios; aOR: adjusted odds ratios; Cl: confidence interval; VS: versus.

\section{Declarations}

\section{Ethics approval and consent to participate}

The study was approved by the National Ethic and Research Committee in Côte d'Ivoire (NCER) (N/Réf : 120/MSHP/CNER-dk), National Malaria Control Program (NMCP) and the local Health District authorities. Written informed consent was obtained by all participants. In agreement with recommendations of NMCP, asymptomatic participants positive to Plasmodium spp. were not treated, according to national policy for malaria case management. All of them received ITNs. They were also advised, if any malaria symptom would appear, to go to a health centre for confirmation. 


\section{Consent for publication}

Not applicable.

\section{Availability of data and materials}

The datasets supporting the conclusions of this article are included within the article. Raw data used for analysis of the study are available from the corresponding author on reasonable request.

\section{Authors'contributions}

XCD wrote the protocol and trained the local team in Côte d'Ivoire; KDS, LJCEE, BB and EKN coordinated the process of ethical approval of the protocol, designed and supervised field data collection. SBA Coordinated internal information at NMCP, MoH and local district; KDS, LJCEE EMAB KIK and KT coordinated the data entry and storage study document. LJCEE, CGNG, AK and EMAB were involved in statistically analysis and interpretation. YEK register global position system. EMAB wrote the initial version of the manuscript; KDS, LJCEE, JTC, EKN and XCD revised the manuscript. All authors read and approved the final manuscript.

\section{Author details}

${ }^{1}$ Université Félix Houphouët-Boigny, Unité de Formation et de Recherche Biosciences, laboratoire de Biologie et Santé, 01 BP V34, Abidjan 01, Côte d'Ivoire. ${ }^{2}$ Centre Suisse de Recherches Scientifiques en Côte d'Ivoire, 01 BP 1303, Abidjan 01, Côte d'Ivoire.

${ }^{3}$ FIND, Campus Biotech, 9 Ch. des Mines1202 Geneva, Switzerland. ${ }^{4}$ Institut Pasteur de Côte d'Ivoire, 01 BP 490 Abidjan 01, Côte d'Ivoire. ${ }^{5}$ Unité de Formation et de Recherche Sciences de la Nature, Université Nangui Abrogoua, 02 B.P. 801, Abidjan 02, Côte d'Ivoire. ${ }^{6}$ Programme National de Lutte Contre le Paludisme en Côte d'Ivoire, Ministère de la Santé et de l'Hygiène Publique, Côte d'Ivoire, BP V4, Côte d'Ivoire.

\section{Acknowledgements}

We would like to thank health authorities at central and local level for all approval and contribution to success of the study. We are grateful to all local communities and participants to this study. Thanks to Assienin N'Guessan, representative of NMCP for the field supervision. Many thanks to laboratory technicians (Jean Baptiste Assamoi, Mahamadou Traoré, Sadikou Touré, Séraphin Kouassi Konan, Séraphin Kouadio Konan), questionnaire data entry (Dotié Coulibaly, Benoit Ouattara, Ouana Coulibaly, Abissata Kambiré, Serge Bazié, Assané Koné, Oliologo Silué, Tchewa Yéo, Damien Ouattara and Soro Karidja) to data collection and drivers (Raphël Kouadio and Guillaume Tokou) for their contribution. Many thanks to Konan N'gatta Patrick Catatchet and late M'bra Richard contribution to map editing.

\section{Funding}


The research was supported by FIND (Geneva, Switzerland) using funds provided by the Bill and Melinda Gates Foundation (OPP1116774).

\section{Competing interests}

The authors declare that they have no competing interests.

\section{References}

1. WHO. World malaria report 2020: 20 years of global progress and challenges [Internet]. Geneva: World Health Organization; 2020 [cited 2020 Dec 14]. 299 p. Available from: https://www.who.int/publications/i/item/9789240015791.

2. WHO. Global technical strategy for malaria, 2016-2030 [Internet]. Geneva: World Health Organization; 2015 [cited 2020 Dec 14]. 35 p. Available from: http://apps.who.int/iris/bitstream/10665/176712/1/9789241564991_eng.pdf?ua=1.

3. Slater HC, Ross A, Felger I, Hofmann NE, Robinson L, Cook J, et al. The temporal dynamics and infectiousness of subpatent Plasmodium falciparum infections in relation to parasite density. Nat Commun. 2019 Dec;10(1):1433.

4. WHO. WHO malaria terminology [Internet]. Geneva. World Health Organization; 2016 [cited 2020 Sep 24]. 38 p. Available from: https://www.who.int/malaria/publications/atoz/malaria-terminology/en/.

5. Males S, Gaye O, Garcia A. Long-Term Asymptomatic Carriage of Plasmodium falciparum Protects from Malaria Attacks: a Prospective Study among Senegalese Children. Clin Infect Dis. 2008 Feb 15;46(4):516-22.

6. Alves FP, Gil LHS, Marrelli MT, Ribolla PE, Camargo EP, Pereira Da Silva LH. Asymptomatic carriers of Plasmodium spp. as infection source for malaria vector mosquitoes in the Brazilian Amazon. $J$ Med Entomol. 2005;42(5):777-9.

7. WHO. Global technical strategy for malaria, 2016-2030. Geneva: World Health organization; 2015. p. 29.

8. Bousema T, Okell L, Felger I, Drakeley C. Asymptomatic malaria infections: detectability, transmissibility and public health relevance. Nat Rev Microbiol. 2014;12(12):833.

9. Lindblade KA, Steinhardt L, Samuels A, Kachur SP, Slutsker L. The silent threat: asymptomatic parasitemia and malaria transmission. Expert Rev Anti Infect Ther. 2013 Jun;11(6):623-39.

10. Gbalégba CGN, Ba H, Silué KD, Ba O, Tia E, Chouaibou M, et al. Distribution of Plasmodium spp. infection in asymptomatic carriers in perennial and low seasonal malaria transmission settings in West Africa. Infect Dis Poverty [Internet]. 2018 Dec [cited 2018 May 9];7(1). Available from: https://idpjournal.biomedcentral.com/articles/10.1186/s40249-018-0412-9.

11. Bassa FK, Ouattara M, Silué KD, Adiossan LG, Baikoro N, Koné S, et al. Epidemiology of malaria in the Taabo health and demographic surveillance system, south-central Côte d'Ivoire. Malar J [Internet]. 2016 Dec [cited 2018 Jan 5];15(1). Available from: http://www.malariajournal.com/content/15/1/9. 
12. Henry M-C, Rogier C, Nzeyimana I, Assi SB, Dossou-Yovo J, Audibert M, et al. Inland valley rice production systems and malaria infection and disease in the savannah of Cote d'Ivoire. Trop Med Int Health. 2003;8(5):449-58.

13. Houngbedji CA, Prisca BN, Hürlimann E, Yapi RB, Silué KD, Soro G, et al. Disparities of Plasmodium falciparum infection, malaria-related morbidity and access to malaria prevention and treatment among school-aged children: a national cross-sectional survey in Côte d'Ivoire. Malar J. 2015;14(1):7.

14. MSHP. Plan National de Développement Sanitaire 2016-2020. République de Côte d'Ivoire: Ministère de la Santé et de l'Hygiène Publique; 2015 p. 88.

15. Carneiro I, Roca-Feltrer A, Griffin JT, Smith L, Tanner M, Schellenberg JA, et al Age-Patterns of Malaria Vary with Severity, Transmission Intensity and Seasonality in Sub-Saharan Africa: A Systematic Review and Pooled Analysis. Noor AM, editor. PLoS ONE. 2010 Feb 1;5(2):e8988.

16. Assi S-B, Henry M-C, Rogier C, Dossou-Yovo J, Audibert M, Mathonnat J, et al. Inland valley rice production systems and malaria infection and disease in the forest region of western Côte d'Ivoire. Malar J. 2013;12(1):233.

17. Hofmann NE, Gruenberg M, Nate E, Ura A, Rodriguez-Rodriguez D, Salib M, et al. Assessment of ultrasensitive malaria diagnosis versus standard molecular diagnostics for malaria elimination: an indepth molecular community cross-sectional study. Lancet Infect Dis. 2018 Oct;18(10):1108-16.

18. Lucchi NW, Ndiaye D, Britton S, Udhayakumar V. Expanding the malaria molecular diagnostic options: opportunities and challenges for loop-mediated isothermal amplification tests for malaria control and elimination. Expert Rev Mol Diagn. 2018 Feb;18(2):195-203.

19. RPGH. Recensement Général de la Population et de l'Habitat, Côte d'Ivoire. Rapport du secrétariat technique permanent du comité technique du RGPH [Internet]. Côte d'Ivoire; 2014 [cited 2016 Jun 3] p. 26. Available from: .

20. Koffi AA, Ahoua Alou LP, Kabran J-PK, N'Guessan R, Pennetier C. Re-Visiting Insecticide Resistance Status in Anopheles gambiae from Côte d'Ivoire: A Nation-Wide Informative Survey. Snounou G, editor. PLoS ONE. 2013 Dec 16;8(12):e82387.

21. Polley SD, Gonzalez IJ, Mohamed D, Daly R, Bowers K, Watson J, et al. Clinical Evaluation of a LoopMediated Amplification Kit for Diagnosis of Imported Malaria. J Infect Dis. 2013 Aug 15;208(4):63744.

22. Perera RS, Ding XC, Tully F, Oliver J, Bright N, Bell D, et al Development and clinical performance of high throughput loop-mediated isothermal amplification for detection of malaria. Snounou G, editor. PLOS ONE. 2017 Feb 6;12(2):e0171126.

23. Zaw MT, Thant M, Hlaing TM, Aung NZ, Thu M, Phumchuea K, et al. Asymptomatic and submicroscopic malaria infection in Kayah State, eastern Myanmar. Malar J [Internet]. 2017 Dec [cited 2017 May 2];16(1). Available from:

http://malariajournal.biomedcentral.com/articles/10.1186/s12936-017-1789-9.

24. Lee P-W, Ji D-D, Liu C-T, Rampao HS, do Rosario VE, Lin I-F, et al. Application of loop-mediated isothermal amplification for malaria diagnosis during a follow-up study in São Tomé. Malar J. 
2012;11(1):408.

25. Aydin-Schmidt B, Xu W, González IJ, Polley SD, Bell D, Shakely D, et al. Loop Mediated Isothermal Amplification (LAMP) Accurately Detects Malaria DNA from Filter Paper Blood Samples of Low Density Parasitaemias. Snounou G, editor. PLoS ONE. 2014 Aug 8;9(8):e103905.

26. De Silva PM, Marshall JM. Factors Contributing to Urban Malaria Transmission in Sub-Saharan Africa: A Systematic Review. J Trop Med. 2012;2012:1-10.

27. Nzobo BJ, Ngasala BE, Kihamia CM. Prevalence of asymptomatic malaria infection and use of different malaria control measures among primary school children in Morogoro Municipality, Tanzania. Malar J [Internet]. 2015 Dec [cited 2017 May 8];14(1). Available from: http://www.malariajournal.com/content/14/1/491.

28. Matthys B, Vounatsou P, Raso G, Tschannen AB, Becket EG, Gosoniu L, et al. Urban farming and malaria risk factors in a medium-sized town in Cote d'Ivoire. Am J Trop Med Hyg. 2006;75(6):122331.

29. Alemu A, Tsegaye W, Golassa L, Abebe G. Urban malaria and associated risk factors in Jimma town, south-west Ethiopia. Malar J. 2011;10(1):173.

30. Hogarh JN, Agyekum TP, Bempah CK, Owusu-Ansah EDJ, Avicor SW, Awandare GA, et al. Environmental health risks and benefits of the use of mosquito coils as malaria prevention and control strategy. Malar J [Internet]. 2018 Dec [cited 2018 Sep 19];17(1). Available from: https://malariajournal.biomedcentral.com/articles/10.1186/s12936-018-2412-4.

31. Walldorf JA, Cohee LM, Coalson JE, Bauleni A, Nkanaunena K, Kapito-Tembo A, et al School-Age Children Are a Reservoir of Malaria Infection in Malawi. Snounou G, editor. PLOS ONE. 2015 Jul 24;10(7):e0134061.

32. Doolan DL, Dobano C, Baird JK. Acquired Immunity to Malaria. Clin Microbiol Rev. 2009 Jan 1;22(1):13-36.

33. Zhou G, Yewhalaw D, Lo E, Zhong D, Wang X, Degefa T, et al. Analysis of asymptomatic and clinical malaria in urban and suburban settings of southwestern Ethiopia in the context of sustaining malaria control and approaching elimination. Malar J [Internet]. 2016 Dec [cited 2018 Jun 21];15(1). Available from: http://malariajournal.biomedcentral.com/articles/10.1186/s12936-016-1298-2.

\section{Tables}

Table 1 Characteristic and Plasmodium spp. prevalence of included household 


\begin{tabular}{|c|c|c|c|c|c|c|c|}
\hline & \multirow[b]{2}{*}{$\mathrm{N}(\%)$} & \multicolumn{3}{|c|}{ Microscopy } & \multicolumn{3}{|l|}{ LAMP } \\
\hline & & $\mathrm{n}(\%)$ & $95 \% \mathrm{Cl}$ & $\begin{array}{l}\mathrm{p} \\
\text { value }\end{array}$ & $\mathrm{n}(\%)$ & $95 \% \mathrm{Cl}$ & $\begin{array}{l}\mathrm{p} \\
\text { value }\end{array}$ \\
\hline Household & $376(100)$ & $\begin{array}{l}47 \\
(12.5)\end{array}$ & $\begin{array}{l}9.1- \\
15.9\end{array}$ & & $\begin{array}{l}144 \\
(38.3)\end{array}$ & $\begin{array}{l}33.4- \\
43.2\end{array}$ & \\
\hline \multicolumn{8}{|l|}{ Localisation } \\
\hline Urban center & $121(32.2)$ & $\begin{array}{l}9 \\
(7.4)\end{array}$ & $\begin{array}{r}2.7- \\
12.1\end{array}$ & & $\begin{array}{l}41 \\
(33.9)\end{array}$ & $\begin{array}{l}25.4- \\
42.4\end{array}$ & \\
\hline Intermediate zone & $181(48.1)$ & $\begin{array}{l}23 \\
(12.7)\end{array}$ & $\begin{array}{l}7.8- \\
17.6\end{array}$ & & $\begin{array}{l}70 \\
(38.7)\end{array}$ & $\begin{array}{l}31.5- \\
45.8\end{array}$ & \\
\hline Periurban & $74(19.7)$ & $\begin{array}{l}15 \\
(20.3)\end{array}$ & $\begin{array}{l}10.9- \\
29.6\end{array}$ & 0.031 & $\begin{array}{l}33 \\
(44.6)\end{array}$ & $\begin{array}{l}33.2- \\
56\end{array}$ & 0.325 \\
\hline \multicolumn{8}{|l|}{ Means } \\
\hline Person per household & $\begin{array}{l}7.7(95 \% \mathrm{Cl}: \\
7.3-8.2)\end{array}$ & - & - & - & - & - & - \\
\hline Person per room & $\begin{array}{l}1.97(95 \% \mathrm{Cl}: \\
1.89 .-2)\end{array}$ & - & - & - & - & - & - \\
\hline \multicolumn{6}{|l|}{$\begin{array}{l}\text { Malaria crisis during the } \\
\text { last } 12 \text { months }\end{array}$} & - & - \\
\hline \multicolumn{8}{|l|}{ Promiscuity } \\
\hline \multicolumn{8}{|l|}{ Size } \\
\hline \multicolumn{6}{|l|}{$\begin{array}{l}\leq 7 \text { residents per } \\
\text { household }\end{array}$} & $\begin{array}{c}31- \\
44.6\end{array}$ & \\
\hline \multicolumn{8}{|c|}{$>7$ residents per household } \\
\hline & 147 (39.2) & $\begin{array}{l}18 \\
(12.2)\end{array}$ & $\begin{array}{r}6.9- \\
17.6\end{array}$ & 0.892 & $\begin{array}{l}58 \\
(39.5)\end{array}$ & $\begin{array}{l}31.5- \\
47.4\end{array}$ & 0.672 \\
\hline \multicolumn{8}{|l|}{ Crowd } \\
\hline$<2$ residents per room & $192(51.3)$ & $\begin{array}{l}26 \\
(13.5)\end{array}$ & $\begin{array}{r}8.7- \\
18.4\end{array}$ & & $\begin{array}{l}71 \\
(37)\end{array}$ & $\begin{array}{l}30.1- \\
43.8\end{array}$ & \\
\hline$\geq 2$ residents per room & $182(48.7)$ & $\begin{array}{l}21 \\
(11.5)\end{array}$ & $\begin{array}{r}6.9- \\
16.2\end{array}$ & 0.559 & $\begin{array}{l}72 \\
(39.6)\end{array}$ & $\begin{array}{l}32.4- \\
46.7\end{array}$ & 0.608 \\
\hline \multicolumn{8}{|l|}{$\begin{array}{l}\text { Malaria crisis during the } \\
\text { last } 12 \text { months }\end{array}$} \\
\hline$\leq 2$ & $186(49.9)$ & 26 & $9-19$ & & 76 & 33.7- & \\
\hline
\end{tabular}




\begin{tabular}{|c|c|c|c|c|c|c|c|}
\hline & & (14) & & & $(40.9)$ & 48 & \\
\hline$>2$ & $187(50.1)$ & $\begin{array}{l}20 \\
(10.7)\end{array}$ & $\begin{array}{l}6.2- \\
15.1\end{array}$ & 0.335 & $\begin{array}{l}67 \\
(35.8)\end{array}$ & $\begin{array}{l}28.9- \\
42.7\end{array}$ & 0.318 \\
\hline \multicolumn{8}{|l|}{ Prevention } \\
\hline \multicolumn{8}{|l|}{ ITNs ownership } \\
\hline No & $143(38)$ & - & - & - & - & - & - \\
\hline Yes & $233(62)$ & - & - & - & - & - & - \\
\hline \multicolumn{8}{|l|}{ ITNs used } \\
\hline No & $145(38.6)$ & $\begin{array}{l}23 \\
(15.9)\end{array}$ & $\begin{array}{r}9.9- \\
21.8\end{array}$ & & $\begin{array}{l}62 \\
(42.8)\end{array}$ & $\begin{array}{l}34.6- \\
50.9\end{array}$ & \\
\hline Yes & $231(61.4)$ & $\begin{array}{l}24 \\
(10.4)\end{array}$ & $\begin{array}{r}6.4- \\
14.3\end{array}$ & 0.118 & $\begin{array}{l}82 \\
(35.5)\end{array}$ & $\begin{array}{l}29.3^{-} \\
41.7^{2}\end{array}$ & 0.159 \\
\hline \multicolumn{8}{|l|}{$\begin{array}{l}\text { Mosquito repellents coils } \\
\text { used }\end{array}$} \\
\hline No & $162(43.1)$ & $\begin{array}{l}17 \\
(10.5)\end{array}$ & $\begin{array}{l}5.7- \\
15.2\end{array}$ & & $\begin{array}{l}49 \\
(30.2)\end{array}$ & $\begin{array}{l}23.1- \\
37.4\end{array}$ & \\
\hline Yes & $214(56.9)$ & $\begin{array}{l}30 \\
(14)\end{array}$ & $\begin{array}{l}9.3- \\
18.7\end{array}$ & 0.306 & $\begin{array}{l}95 \\
(44.4)\end{array}$ & $\begin{array}{l}37.7- \\
51.1\end{array}$ & 0.005 \\
\hline \multicolumn{8}{|l|}{ Insecticide spray used } \\
\hline No & $196(52.1)$ & $\begin{array}{l}26 \\
(13.3)\end{array}$ & $8.5-18$ & & $\begin{array}{l}79 \\
(40.3)\end{array}$ & $\begin{array}{l}33.4- \\
47.2\end{array}$ & \\
\hline Yes & 180 (47.9) & $\begin{array}{l}21 \\
(11.7)\end{array}$ & $\begin{array}{r}6.9- \\
16.4\end{array}$ & 0.64 & $\begin{array}{l}65 \\
(36.1)\end{array}$ & $\begin{array}{c}29- \\
43.2\end{array}$ & 0.403 \\
\hline \multicolumn{8}{|l|}{$\begin{array}{l}\text { Treatment seeking } \\
\text { behaviour }\end{array}$} \\
\hline Health centre & $229(60.9)$ & $\begin{array}{l}24 \\
(10.5)\end{array}$ & $\begin{array}{r}6.5- \\
14.5\end{array}$ & & $\begin{array}{l}77 \\
(33.6)\end{array}$ & $\begin{array}{c}27.5- \\
39.8\end{array}$ & \\
\hline Self-medication & $104(27.7)$ & $\begin{array}{l}16 \\
(15.4)\end{array}$ & $\begin{array}{r}8.4- \\
22.4\end{array}$ & & $\begin{array}{l}46 \\
(44.2)\end{array}$ & $\begin{array}{c}34.6- \\
53.8\end{array}$ & \\
\hline Traditional health cure & $43(11.4)$ & $\begin{array}{l}7 \\
(16.3)\end{array}$ & $5-27.5$ & 0.332 & $\begin{array}{l}21 \\
(48.8)\end{array}$ & $\begin{array}{l}33.7- \\
64\end{array}$ & 0.058 \\
\hline
\end{tabular}

$\therefore$ Not applicable, ITNs Insecticide-treated mosquito net, $\mathrm{C}$ Confidence interval 


\begin{tabular}{|c|c|c|c|c|c|c|c|}
\hline & \multicolumn{4}{|c|}{ microscopy } & \multicolumn{3}{|c|}{ LAMP } \\
\hline & $\mathrm{N}(\%)$ & $\mathrm{n}(\%)$ & $95 \% \mathrm{Cl}$ & $\begin{array}{l}\mathrm{p} \\
\text { value }\end{array}$ & $n(\%)$ & $95 \% \mathrm{Cl}$ & $\begin{array}{l}\mathrm{p} \\
\text { value }\end{array}$ \\
\hline Participants & $\begin{array}{l}1011 \\
(100)\end{array}$ & $\begin{array}{l}53^{a} \\
(5.2)\end{array}$ & $3.9-6.6$ & & $\begin{array}{l}190^{\mathrm{b}} \\
(18.8)\end{array}$ & $\begin{array}{l}16.4- \\
21.2\end{array}$ & \\
\hline \multicolumn{8}{|l|}{ Age } \\
\hline $\begin{array}{l}\text { Mean age } \\
\text { (Year) }\end{array}$ & \multicolumn{3}{|c|}{35.1 (SD :13.9, min:18 max:87) } & - & - & - & - \\
\hline$<30$ & $\begin{array}{l}441 \\
(43.6)\end{array}$ & $26(5.9)$ & $3.7-8$ & & $\begin{array}{l}106 \\
(24.0)\end{array}$ & $\begin{array}{l}20.0- \\
28.0\end{array}$ & \\
\hline $30-40$ & $\begin{array}{l}262 \\
(25.9)\end{array}$ & $11(4.2)$ & $1.8-6.6$ & & $40(15.3)$ & $\begin{array}{l}10.9- \\
19.6\end{array}$ & \\
\hline$>40$ & $\begin{array}{l}308 \\
(30.5)\end{array}$ & $16(5.2)$ & $2.7-7.7$ & 0.62 & $44(14.3)$ & $\begin{array}{l}10.4- \\
18.2\end{array}$ & 0.001 \\
\hline \multicolumn{8}{|l|}{ Sex } \\
\hline Female & $\begin{array}{l}697 \\
(69.0)\end{array}$ & $30(4.3)$ & $2.8-5.8$ & & $\begin{array}{l}109 \\
(15.6)\end{array}$ & $\begin{array}{l}12.9- \\
18.3\end{array}$ & \\
\hline Male & $\begin{array}{l}314 \\
(31.0)\end{array}$ & $23(7.3)$ & $4.4-10.2$ & 0.046 & $81(25.8)$ & $\begin{array}{l}20.9- \\
30.6\end{array}$ & $<0.001$ \\
\hline \multicolumn{8}{|l|}{ Site } \\
\hline Urban center & $\begin{array}{l}338 \\
(33.4)\end{array}$ & $10(3)$ & $1.1-4.8$ & & $50(14.8)$ & $\begin{array}{l}11.0- \\
18.6\end{array}$ & \\
\hline $\begin{array}{l}\text { Intermediate } \\
\text { zone }\end{array}$ & $\begin{array}{l}501 \\
(49.6)\end{array}$ & $26(5.2)$ & $3.2-7.1$ & & $91(18.2)$ & $\begin{array}{l}14.8^{-} \\
21.5\end{array}$ & \\
\hline Periurban & $172(17)$ & $17(9.9)$ & $5.4-14.3$ & 0.004 & $49(28.5)$ & $\begin{array}{l}21.7^{-} \\
35.3\end{array}$ & 0.001 \\
\hline
\end{tabular}

$\therefore$ Not applicable, SD Standard deviation, $C /$ Confidence interval, ${ }^{a}$ All of them were Plasmodium falciparum detected by microscopy, ${ }^{\mathrm{b}} \mathrm{Pf}$ LAMP revealed that $82.1 \%$ (156/190) were Plasmodium falciparum and $17.9 \%$ (34/190) were non-Plasmodium falciparum

Table 3 Additional malaria prevention measures to households use and not mosquito repellents coils 


\begin{tabular}{|ll|}
\hline Malaria prevention measures & Households, $\mathrm{n}(\%)$ \\
\hline Households use mosquito repellents coils, $\mathrm{N}=\mathbf{2 1 4}$ & \\
\hline Mosquito repellents coils only & $44(20.6)$ \\
\hline Mosquito repellents coils + ITNs, $\mathrm{n}(\%)$ & $63(29.4)$ \\
\hline Mosquito repellents coils +Insecticide spray, $\mathrm{n}(\%)$ & $61(28.5)$ \\
\hline Mosquito repellents + ITNs + Insecticide spray, $\mathrm{n}(\%)$ & $46(21.5)$ \\
\hline Households do not use mosquito repellents coils, N=162 & \\
\hline None, $\mathrm{n}(\%)$ & $8(4.9)$ \\
\hline ITNs, $\mathrm{n}(\%)$ & $81(50)$ \\
\hline Insecticide spray, $\mathrm{n}(\%)$ & $32(19.8)$ \\
\hline ITNs + insecticide spray, $\mathrm{n}(\%)$ & $41(25.3)$ \\
\hline
\end{tabular}

ITNs Insecticide-treated mosquito net

Table 4 Asymptomatic risk factor associated to household 


\begin{tabular}{|c|c|c|c|c|}
\hline & Microscopy & & LAMP & \\
\hline Characteristics & $\operatorname{cOR}(95 \% \mathrm{Cl})$ & $P$ value & cOR $(95 \% \mathrm{Cl})$ & $P$ value \\
\hline \multicolumn{5}{|l|}{ Localisation } \\
\hline Urban center & 1 & & 1 & \\
\hline Intermediate zone & $1.8(0.8-4)$ & 0.149 & $1.2(0.7-2)$ & 0.398 \\
\hline Periurban & $3.2(1.3-7.7)$ & 0.011 & $1.6(0.9-2.8)$ & 0.136 \\
\hline \multicolumn{5}{|l|}{ Promiscuity } \\
\hline \multicolumn{5}{|l|}{ Size } \\
\hline$\leq 7$ residents & 1 & & 1 & \\
\hline$>7$ residents & $0.1(0.1-0.2)$ & 0.892 & $1(0.7-1.7)$ & 0.672 \\
\hline \multicolumn{5}{|l|}{ Crowd } \\
\hline$<2$ residents per room & 1 & & 1 & \\
\hline$\geq 2$ residents per room & $0.8(0.4-1.5)$ & 0.559 & $1.1(0.7-1.7)$ & 0.608 \\
\hline \multicolumn{5}{|c|}{ Malaria crisis during the last 12 months } \\
\hline$\leq 2$ & 1 & & 1 & \\
\hline$>2$ & $0.7(0.4-1.4)$ & 0.336 & $0.8(0.5-1.2)$ & 0.318 \\
\hline \multicolumn{5}{|l|}{ Prevention } \\
\hline \multicolumn{5}{|l|}{ ITNs used } \\
\hline No & 1 & & 1 & \\
\hline Yes & $0.6(0.3-1.1)$ & 0.121 & $0.7(0.5-1.1)$ & 0.159 \\
\hline \multicolumn{5}{|c|}{ Mosquito repellents coils used } \\
\hline No & 1 & & 1 & \\
\hline Yes & $1.4(0.7-2.6)$ & 0.308 & $1.8(1.2-2.8)$ & 0.005 \\
\hline \multicolumn{5}{|l|}{ Insecticide spray used } \\
\hline No & 1 & & 1 & \\
\hline Yes & $0.9(0.5-1.6)$ & 0.64 & $0.8(0.5-1.2)$ & 0.403 \\
\hline \multicolumn{5}{|c|}{ Treatment seeking behaviour } \\
\hline Health centre & 1 & & 1 & \\
\hline Self-medication & $1.5(0.8-3)$ & 0.205 & $1.6(0.9-2.5)$ & 0.065 \\
\hline
\end{tabular}


ITNs Insecticide-treated mosquito net, $C O R$ crude odds ratios, aOR adjusted odds ratios, $\mathrm{Cl}$ Confidence interval

Table 5 LAMP and microscopy data crossing

\begin{tabular}{|ll|}
\hline Diagnosis & Proportion, $\mathbf{n}(\%)$ \\
\hline Pan LAMP positive, $\mathrm{N}=190$ & \\
\hline Microscopy negative, $\mathrm{n}(\%)$ & $147(77.4)$ \\
\hline Microscopy positive, $\mathrm{n}(\%)$ & $43(22.6)$ \\
\hline Pan LAMP negative, $\mathrm{N}=\mathbf{8 2 1}$ & \\
\hline Microscopy negative, $\mathrm{n}(\%)$ & $811(98.8)$ \\
\hline Microscopy positive, $\mathrm{n}(\%)$ & $10(1.2)$ \\
\hline
\end{tabular}

Table 6 Asymptomatic risk factor associated to participant tested 


\begin{tabular}{|c|c|c|c|c|c|c|c|c|}
\hline \multirow[b]{2}{*}{ Characteristics } & \multicolumn{4}{|c|}{ Microscopy } & \multicolumn{4}{|l|}{ LAMP } \\
\hline & $\begin{array}{l}\text { COR } \\
(95 \% \mathrm{Cl})\end{array}$ & $\begin{array}{l}P \\
\text { value }\end{array}$ & $\begin{array}{l}\text { aOR } \\
(95 \% \mathrm{Cl})\end{array}$ & $\begin{array}{l}P \\
\text { value }\end{array}$ & $\begin{array}{l}\text { COR } \\
(95 \% \mathrm{Cl})\end{array}$ & $\begin{array}{l}P \\
\text { value }\end{array}$ & $\begin{array}{l}\text { aOR } \\
(95 \% \mathrm{Cl})\end{array}$ & $\begin{array}{l}P \\
\text { value }\end{array}$ \\
\hline \multicolumn{9}{|l|}{ Age } \\
\hline$<30$ & 1 & & & & 1 & & 1 & \\
\hline $30-40$ & $\begin{array}{l}0.7(0.3- \\
1.4)\end{array}$ & 0.332 & - & - & $\begin{array}{l}0.6(0.4- \\
0.8)\end{array}$ & 0.006 & $\begin{array}{l}0.6(0.4- \\
0.9)\end{array}$ & 0.017 \\
\hline$>40$ & $\begin{array}{l}0.9(0.5- \\
1.6)\end{array}$ & 0.682 & - & - & $\begin{array}{l}0.5(0.4- \\
0.8)\end{array}$ & 0.001 & $\begin{array}{l}0.5(0.4- \\
0.8)\end{array}$ & 0.002 \\
\hline \multicolumn{9}{|l|}{ Sex } \\
\hline Female & 1 & & 1 & & 1 & & 1 & \\
\hline Male & $\begin{array}{l}1.75(1- \\
3.1)\end{array}$ & 0.049 & $\begin{array}{l}1.7(1- \\
3.1)\end{array}$ & 0.052 & $\begin{array}{l}1.9(1.3- \\
2.6)\end{array}$ & $<0.001$ & $\begin{array}{l}1.9(1.3- \\
2.6)\end{array}$ & $<0.001$ \\
\hline \multicolumn{9}{|l|}{ Site } \\
\hline Urban center & 1 & & 1 & & 1 & & 1 & \\
\hline $\begin{array}{l}\text { Intermediate } \\
\text { zone }\end{array}$ & $\begin{array}{l}1.8(0.8- \\
3.8)\end{array}$ & 0.123 & $\begin{array}{l}1.8(0.8- \\
3.8)\end{array}$ & 0.125 & $\begin{array}{l}1.3(0.9- \\
1.9)\end{array}$ & 0.201 & $\begin{array}{l}1.2(0.8- \\
1.8)\end{array}$ & 0.303 \\
\hline Periurban & $\begin{array}{l}3.6(1.6- \\
8)\end{array}$ & 0.002 & $\begin{array}{l}3.6(1.6- \\
8)\end{array}$ & 0.002 & $\begin{array}{l}2.3(1.5- \\
3.6)\end{array}$ & $<0.001$ & $\begin{array}{l}2.2(1.4- \\
3.5)\end{array}$ & $<0.001$ \\
\hline
\end{tabular}

$\because$ Not applicable, cOR crude odds ratios, aOR adjusted

Figures 


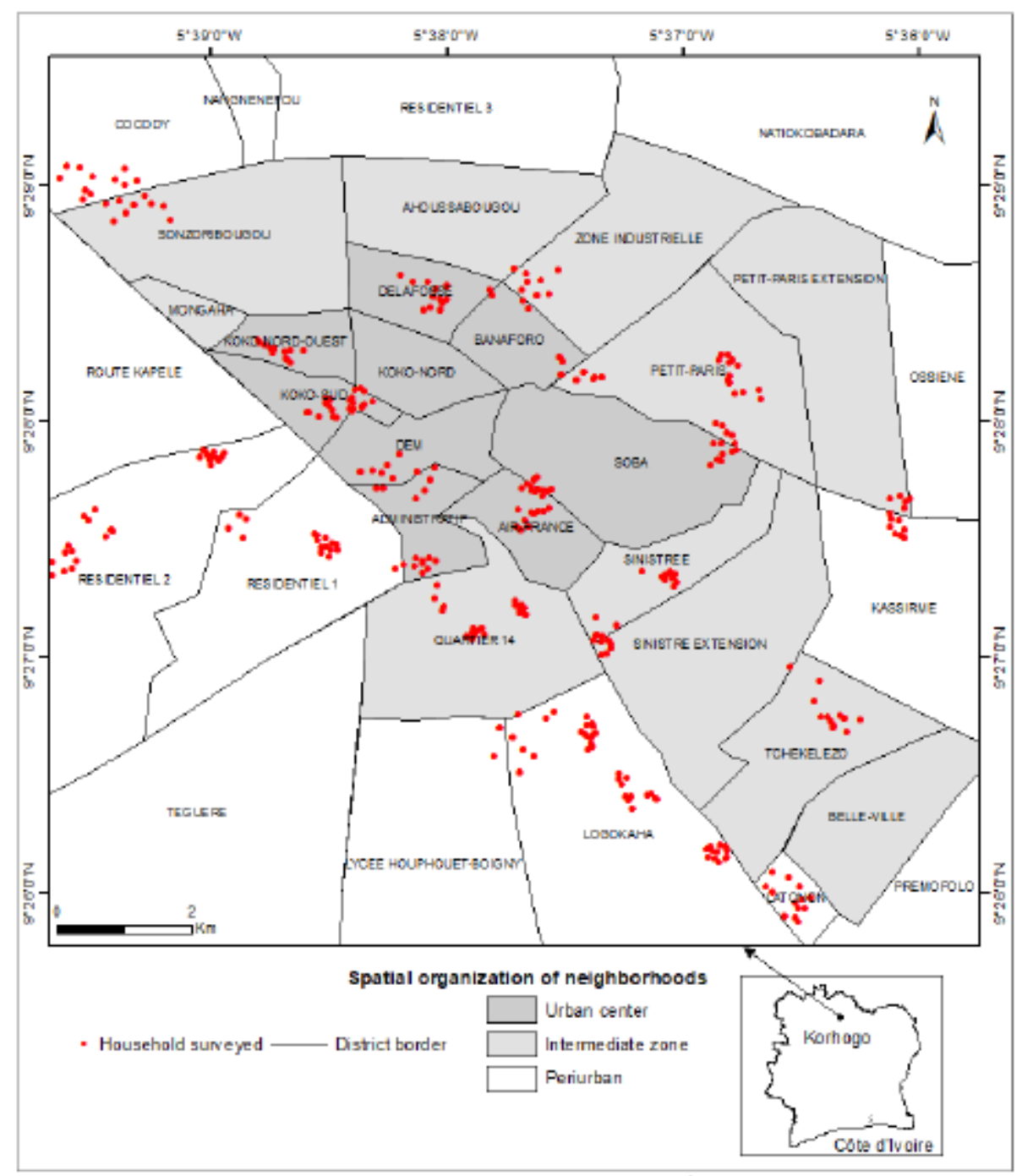

Source: BNETLCCT 2012 P: WGS 1954 Zane 3OW

Con ception et réalisation: BENIE E. M. A etN'gatth K., 2020

\section{Figure 1}

Spatial distribution of household visited in the health district of Korhogo Northern Côte d'Ivoire Note: The designations employed and the presentation of the material on this map do not imply the expression of any opinion whatsoever on the part of Research Square concerning the legal status of any country, territory, city or area or of its authorities, or concerning the delimitation of its frontiers or boundaries. This map has been provided by the authors. 


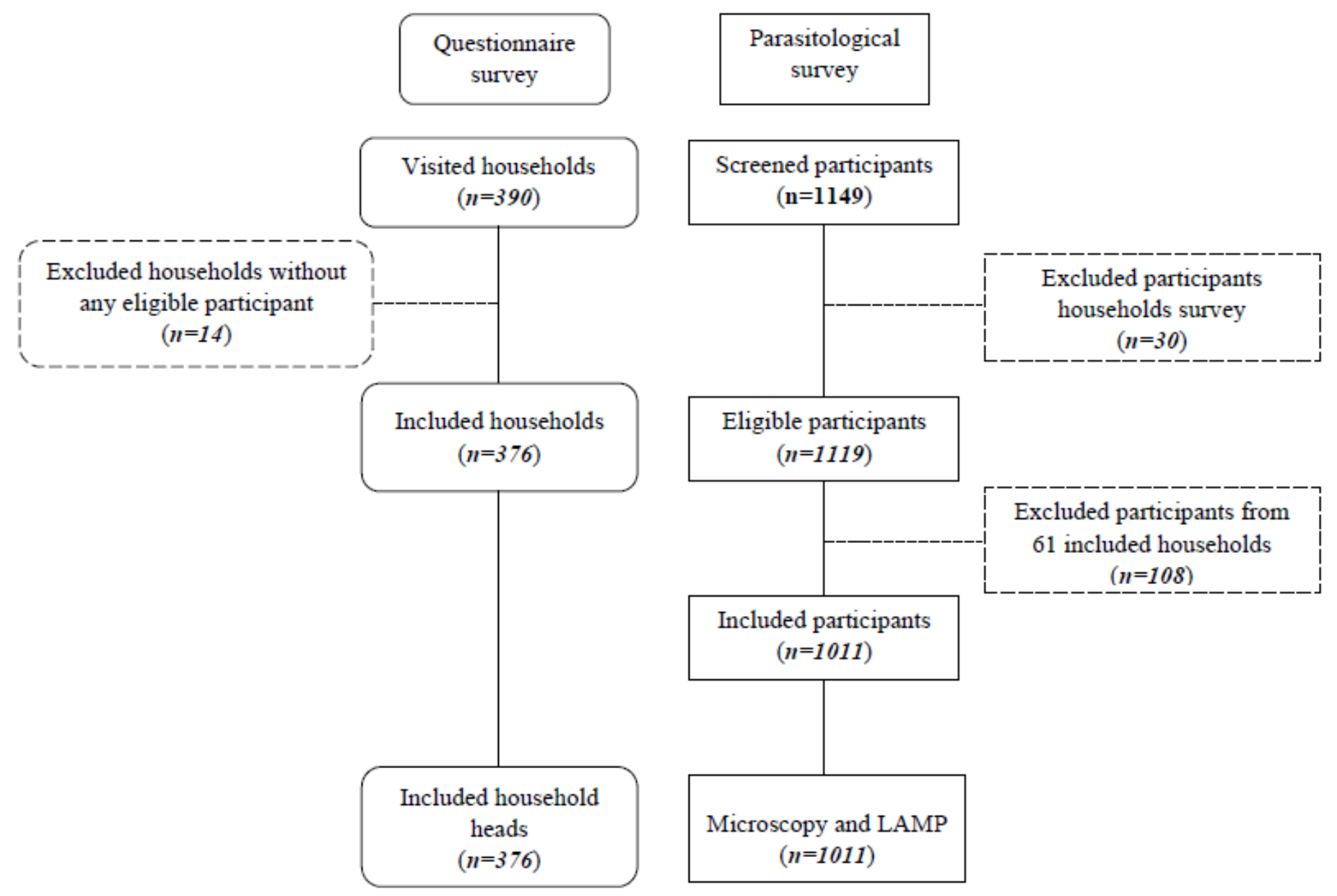

Figure 2

Flow chart of study 